\title{
CANADIAN SNOW RESEARCH
}

A RECENT event of great importance has been the inception of officially sponsored snow research in Canada.

Hitherto large scale snow research has been almost entirely restricted to the Swiss and it is good to know that the Empire with its enormous opportunities will now be playing its part. The connection between the mechanics of soil and the mechanics of snow has been obvious for several years in Switzerland where the resources of the civil engineering laboratories have been made available for snow research. Dr. R. Haefeli, originally a civil engineer and head of the soil research department of the Eidgenossische Technische Hochschule in Zürich, has now become one of the foremost authorities on snow and ice. It is satisfactory to learn that this connection of ideas is being followed up in Canada. In England too a start has been made.

Recently Professor R. Legget of the University of Toronto and Chairman of the Associated Committee on Soil and Snow Mechanics of the National Research Council of Canada, accompanied by Captain M. G. Bekker of the Canadian Army and a representative of the Ministry of Supply in London, visited various centres in Switzerland where soil, snow, and ice mechanics were being studied.

Professor Legget also inspected the winter equipment of the Swiss Army. ${ }^{1}$ Professor Legget seems to have been impressed by the perfection of detail in the Swiss equipment, as for instance the alloy snow shovel. This instrument has also been made and perfected in this country and brought to the notice of explorers.

The Canadians are no doubt ahead of the Swiss in the design and manufacture of vehicles for winter transport, but the Swiss have no need for transport over long distances in level country. However, Professor Legget, who made contact with this Society on his return to London, was impressed with the ingenuity of the Swiss approach to snow problems in general. He spoke most warmly of the reception he and his party had received. There can be no doubt that the collaboration between the Canadian, the Swiss and the English authorities will be fruitful.

\section{FIXING SNOWFLAKES}

THE photographing of snowflakes has been carried out for many years and has yielded valuable as well as beautiful results. But the unsubstantial nature of snow necessarily makes the process laborious and slow.

Mr. V. J. Schaefer, ${ }^{2}$ a member of the Committee on Snow of the American Geophysical Union, has devised a simple and rapid method of "fixing" snowflakes. These are treated with a resinpolyvinyl formal-dissolved in ethylene dichloride, which deposits a coating estimated at 8/100,000 of an inch thick, through which the melted ice escapes. A shell is left showing in detail the original form of the flake which can be examined at leisure.

The process should be most useful for the correlation of the different types of crystals in changing weather systems, since, for this purpose, a large number of crystals must be collected in a short time. This is one of the tasks it is hoped the Society's Snow Survey will undertake later on. Mr. Schaefer intends using this method for a snow survey he is carrying out in the State of New York. He has sent us a number of papers describing its use for this and for other purposes, such as the examination of metal crystals, in which certain advantages over other methods are claimed for it.

${ }^{1}$ Acknowledgement is made to the Chief Scientific Officer, Ministry of Supply, for information sent to the Society on this investigation.

${ }^{2}$ Schaefer, V. J. The use of snowflake replicas for studying storms. Nature, Vol. 149, Jan. 17, 1942, p. 8 1. 